\title{
Parallel deficits in linear growth and mental development in low-income Mexican infants in the second year of life
}

\author{
Lia C Fernald ${ }^{1, *}$, Lynnette M Neufeld ${ }^{2}$, Lauren R Barton ${ }^{3}$, Lourdes Schnaas ${ }^{4}$, \\ Juan Rivera ${ }^{2}$ and Paul J Gertler ${ }^{5}$ \\ ${ }^{1}$ School of Public Health, University of California, Berkeley, 140 Warren Hall, Berkeley, CA 94720-7360, USA: \\ ${ }^{2}$ National Institute of Public Health, Mexico: ${ }^{3}$ Center for Health and Community, Universtiy of California, \\ San Francisco, San Francisco, CA, USA: ${ }^{4}$ National Institute of Perinatology, Mexico: ${ }^{5}$ University of California, \\ Berkeley, Berkeley, CA, USA
}

\section{Submitted 2 November 2004: Accepted 11 May 2005}

\begin{abstract}
Objective: To explore anthropometric indicators and mental development in verylow-income children in the second year of life.

Design: Cross-sectional survey.

Setting: Low-income areas (income $<20$ th percentile) in semi-urban Mexico (defined as towns or cities with 2500-50000 inhabitants).

Subjects: Eight hundred and ninety-six children aged 12.5-23.5 months surveyed from September to December 2001.

Methods: Questionnaire survey and anthropometric survey of households. Multivariate regression models evaluated differences across age in anthropometry (heightfor-age $Z$-score (HAZ) and weight-for-height $Z$-score) and cognitive function (Mental Development Index (MDI) of the Bayley Scales of Infant Development) while controlling for socio-economic and parental characteristics.

Results: There was a significant decline in HAZ and in age-adjusted MDI score across the second year of life. Although the children showed MDI scores close to the mean, normed US values at 13-14 months, the scores were significantly lower than expected in older children $(P<0.0001)$, even after controlling for socio-economic status and parental characteristics. At 13-14 months, only 3\% of children received scores below 70 (less than minus two standard deviations), whereas by 19-20 months, almost 17\% of children were performing below this level. No socio-economic or parental characteristics were significant predictors of HAZ or MDI.

Conclusions: Parallel deficits are evident in both height-for-age and cognitive functioning during the second year of life in low-income Mexican infants. The consistency of these growth and development findings further stresses the need for targeted interventions to reduce the vulnerability of low-income Mexican children very early in life.
\end{abstract}

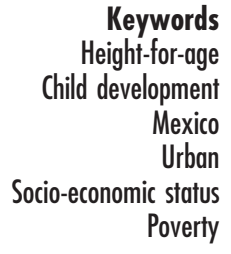

Socio-economic status (SES) predicts a myriad of child health and developmental outcomes, and outcomes improve with each increasing step of the SES gradient ${ }^{1}$. Infants and toddlers growing up in poverty are more likely to experience developmental delays and growth deficits than those from more privileged backgrounds because they are disproportionately exposed to a wide range of cooccurring risk factors that may impact development ${ }^{1-3}$. For example, children from low-income backgrounds in the USA are more likely to experience poor nutrition or malnutrition ${ }^{1,4}$, less stimulating learning environments ${ }^{5,6}$, more limited linguistic role models ${ }^{7,8}$, crowded or substandard housing 9,10 , exposure to domestic or community violence ${ }^{6,11}$ and greater environmental hazards $^{12-15}$.
In the developing world, the conditions contributing to poor development are exacerbated by poverty, poor sanitation, crowding and even more limited access to resources ${ }^{16}$. For these reasons, children in the developing world are more likely to be vulnerable to deficiencies in basic health and nutrition, which contribute significantly to related delayed physical and cognitive development ${ }^{17}$. Significant associations exist between low height-for-age (stunting) and delayed cognitive development ${ }^{18-30}$, psychomotor development ${ }^{21,28,31,32}$, poor fine motor skills $^{20,33}$ and altered behaviour ${ }^{34}$.

Children with a history of malnutrition also perform worse in tests of school achievement ${ }^{24,26,35}$, which may be a consequence of starting school later than comparison children $^{36}$. As they grow up, children with a history of 
malnutrition are likely to have substantially lower wages than healthier adults ${ }^{37-41}$, and are thus less likely to be able to provide increased stimulation and resources for their own children, thereby perpetuating the cycle of the impact of poverty. As a result of these many factors, children who grow up in poverty often do not reach their full potential or achieve the skills they need to be successful in society ${ }^{42}$.

Given the large deficits evident in children who live in poverty and the implications of these conditions on development across the life span, policy-makers, healthcare workers, teachers and parents are all interested in how to improve the health and well-being of vulnerable children. One critical issue, however, is the timing of the interventions. There is compelling evidence that interventions in early childhood are likely to be effective; but the question of how early to intervene still remains. This issue is important not just for practical issues of feasibility and cost-effectiveness, but also because of issues of brain plasticity and physiological development ${ }^{43}$. Research on low-income children in the USA suggests that developmental scores are in the normal range during infancy, but then the scores decline during the toddler and preschool years; this pattern is not apparent in middle-income samples ${ }^{44}$. These data suggest that low-income children may be protected from their adverse environments very early in life, but then are increasingly vulnerable to the external environment as they enter their toddler years ${ }^{45,46}$.

In order to intervene appropriately and successfully, specific research is needed to guide the development and timing of supportive interventions targeted at children from low-income environments. The purpose of the research described herein was to examine anthropometric indicators and mental development in a large cross-sectional sample of children in their second year of life, living in poverty in Mexico. We also looked at several parental and demographic characteristics to examine what variables are associated with poor development in children. Little published research exists about the status of Mexican infants and toddlers, and this information is important for policy-makers at many levels. We hypothesised that lowincome Mexican children across all age groups would show evidence of physical and mental delay when compared with age-normed data from the developed world. In spite of the narrow range of SES represented in our sample, we also hypothesised that there would be some independent contribution of the various socio-economic or parental characteristics to the regression models.

\section{Methods}

\section{Study population}

Children in this study were identified in a house-to-house survey in low-income areas of semi-urban Mexico, defined as cities or towns with 2500-50000 inhabitants. The survey was part of a baseline evaluation that occurred before the introduction of Mexico's national welfare programme (OPORTUNIDADES, previously PROGRESA). OPORTUNIDADES was originally rolled out in rural areas beginning in 1998, and a rigorous evaluation was undertaken in these communities ${ }^{47,48}$. Given the success of the programme, the government began to provide similar benefits in semi-urban areas in January 2002. The survey described here occurred in September-December 2001 , immediately before the introduction of benefits.

The programme determined eligibility first by identifying underserved communities and then by choosing lowincome households within those communities. On average, $78 \%$ of the households in an eligible locality were classified as eligible for programme benefits. Children involved in the present study all lived in households that qualified for programme benefits, meaning that their family incomes were among the lowest 20\% of those in Mexico. For the survey described here, a randomised sample of 131 communities (representing 10\% of the total) were selected from OPORTUNIDADESeligible communities and stratified by geography, average income and size ${ }^{49}$. All households in these communities were identified and visited by a team of health professionals. If an infant between 12.5 and 23.5 months was present in the participating household, the infant was assessed for growth and cognitive development. Only one infant per household was assessed. Less than $1 \%$ of infants were excluded because of severe delays in mental or motor development that were most likely associated with genetic disorders or congenital anomalies.

The study was approved by the Committee of Ethics in Human Research of the Instituto Nacional de Salud Pública (Mexico's National Institute of Public Health), as well as by the Center for the Protection of Human Subjects at the University of California at Berkeley. Written, informed consent forms were signed by the parents of infants after careful verbal explanation of the goals, procedures and risks of the research.

\section{Antbropometry}

Current weight and height were measured using standard procedures by registered nurses who had been carefully trained and standardised ${ }^{50}$. Infant lengths were measured with custom-made table-top infantometers. Birth date was obtained from birth records and used to calculate age in months. The ANTHRO software program was used to calculate height-for-age $Z$-scores (HAZ) and weight-forheight $Z$-scores (WHZ) ${ }^{51}$.

\section{Bayley Scales of Infant Development}

The Mental Development Index (MDI) of the second edition of the Bayley Scales of Infant Development (BSIDII, translated into locally appropriate Spanish) was administered to infants aged 12.5 to 23.5 months $^{52}$. The Physical Development Index (PDI) scale was not administered. Performance on the Bayley Scales of Infant 
Development has been correlated with scores on tests indicative of later academic achievement, including the McCarthy Scales of Children's Abilities, the full scale of the Wechsler Preschool and Primary Scale of IntelligenceRevised, the Differential Ability Scales, and the Preschool Language Scale-Third Edition ${ }^{53}$. Longitudinal studies have shown that tests similar to the BSID-II administered as early as 22 months are associated with education outcomes in adulthood, and that the associations between early performance and later outcomes are the strongest in children from households of low SES ${ }^{54}$.

The mental scale of the Bayley contains 178 items and is designed to assess memory, learning, problem-solving, sensory-perceptual acuities, and receptive and expressive language development in children aged 1-42 months. The items administered and index scores assigned are based on 1-month intervals. These intervals range from the middle of one month to the middle of the next, so that infants assessed at 12 months will range from 11.5 months to 12.5 months old. Within each age group, the average score for the MDI is set at 100, with a standard deviation (SD) of 15 . Scores below $85(<-1 \mathrm{SD})$ suggest mildly delayed performance indicative of developmental risk and scores below $70(<-2$ SD) suggest significantly delayed performance. Although the Bayley test has not been normed on a Mexican population, prior researchers have used this instrument to assess development in Mexican infants ${ }^{55-58}$. Lower mean Bayley scores have been seen in Mexican infants exposed to $\mathrm{lead}^{56}$ and alcohol ${ }^{57}$, supporting the sensitivity of this measure to expected developmental changes associated with environmental risks in the Mexican context.

All tests were administered by registered nurses who had been carefully trained and supervised. Training consisted of tutorials by a child development specialist from our group (L.S.), who provided extensive instruction and practice in administering items and scoring responses, and quality control checks through regular reviews. Bayley assessments were conducted in a single session in the infant's home in Spanish. MDI scores were available for 868 (97\%) of the eligible infants. Scores from the PDI of the Bayley were not available in this population. In most of the cases where MDI scores were not available, scores could not be computed because items had been omitted due to the child's state (e.g. sleepy) or his/her persistent, active refusal to comply with the tasks. Of infants with MDI scores, 800 (92\%) also had anthropometric data available.

\section{Family and environmental variables}

Mothers provided comprehensive demographic and health information about themselves and their spouses in a structured interview conducted in one session. The questions were related to the family's SES and living conditions, in addition to parental characteristics such as education. Social capital was assessed through a standard questionnaire. Instruments were adapted to be sensitive to the extreme poverty in which the families were living, and all interviews were conducted in Spanish. The variables in the questionnaires were designed to be sensitive to the OPORTUNIDADES programme; thus, we were limited in our inclusion of covariates to variables selected for the original purpose of the study. However, we were able to select variables that are generally considered to be associated with child development, including income (per capita and household-level consumption), parental age, parental education (whether head of household had remained in school past primary school), parental literacy and employment, crowding (number of people in the household), language (whether the head of the household spoke an indigenous language) and social capital (participation in community activities) $)^{59,60}$.

\section{Statistical analyses}

All statistical analyses were conducted using the survey commands in STATA 8.0 (STATACorp LP, College Station, TX, USA). Descriptive statistics, appropriate transformations and identification of outliers were performed before bivariate and multivariate analyses were conducted. Income measurements were logarithmically transformed due to their tendency to be positively skewed. All $P$-values were two-tailed and considered statistically significant if $<0.05$. The associations between our key dependent variables (MDI scores and HAZ) and various measurements were first examined in bivariate analyses. An initial model was fitted using only age and sex as predictor variables, and then an adjusted model was fitted using several parental and environmental characteristics. The inclusion of these covariates reduced the sample size because not all households provided full demographic information. Regression diagnostics were performed to assess the effects of multicollinearity and potentially influential data points.

\section{Results}

Infants came from households with limited resources, with more than two-thirds of parents $(69.30 \%$ of mothers, $67.35 \%$ of fathers) exposed to no education past primary school, and about $14 \%$ of parents unable to read or write (Table 1). Indigenous languages were spoken in less than $10 \%$ of the homes and all participating respondents were capable of answering questionnaires in Spanish. A majority (89.92\%) of fathers worked outside the home whereas only $13.72 \%$ of women did. An average ( \pm SD) of $5.23( \pm 1.92)$ people lived in each household, with a weekly household expenditure of 505.81 ( \pm 299.1 ) pesos (equal to about \$US 46). The level of community involvement was low, with $91.80 \%$ of families not participating in any community activities.

The mean MDI score for the infants in this study was 90.83 ( \pm 13.90 ); however, this number masks the range of scores evident across the second year of life. The mean 
Table 1 Child, parental and household characteristics

\begin{tabular}{lc}
\hline Descriptive characteristics & Mean (SD) or \% \\
\hline Child & \\
Age (months) & $17.5(3.50)$ \\
Gender (\% female) & 51.93 \\
Maternal characteristics & \\
Age (years) & $32.42(10.70)$ \\
Education (\% only primary school) & 69.30 \\
Illiteracy (\% can't read/write) & 14.58 \\
Unemployment (\% with no job outside home) & 86.28 \\
Indigenous language (\% with language spoken) & 9.39 \\
Paternal characteristics & \\
Age (years) & $35.32(12.09)$ \\
Education (\% only primary school) & 67.35 \\
Illiteracy (\% can't read/write) & 13.81 \\
Unemployment (\% with no job outside home) & 11.08 \\
Indigenous language (\% with language spoken) & 9.24 \\
Household & \\
Weekly household consumption (pesos) & $505.81(299.1)$ \\
Number of people in household & $5.23(1.92)$ \\
Per capita consumption (log-transformed) & $4.49(0.57)$ \\
Social capital, last 4 weeks (\% no community involvement) & 91.80 \\
Social capital rating (\% no community involvement) & 84.26 \\
\hline
\end{tabular}

SD - standard deviation.

score for the 13-14-month-olds was 97.36 ( \pm 11.92$)$, and by $21-23$ months, the mean was 87.02 ( \pm 14.67 ) (Table 2 ). In all age groups, the standard deviations were smaller than the expected value of 15 , which may be due to the homogeneity of our sample. The percentage of children with MDI scores below - 1SD was higher in the older age groups, with $14.43 \%$ of $13-14$-month-olds and $56.38 \%$ of 19-20-month-olds with a score of 85 or below (Table 2).

Mean HAZ was $-1.28( \pm 1.86)$, and $33.23 \%$ of the children were stunted (HAZ $\leq-2)$. However, as with the MDI score, HAZ varied significantly across the age groups. Mean HAZ in 13-14-month-olds was -1.02 ( \pm 1.94 ),

Table 2 Mental Development Index (MDI) score of the Bayley Scales of Infant Development, height-for-age Z-score (HAZ) and weight-for-height $Z$-score (WHZ) by age (months) in study infants: mean, standard deviation (SD), and percentage below - 1SD and $-2 S D$ of the respective mean

\begin{tabular}{|c|c|c|c|c|}
\hline & $n$ & Mean (SD) & $\%<-1 S D$ & $\%<-2 S D$ \\
\hline \multicolumn{5}{|l|}{ MDI score } \\
\hline $13-14$ months & 201 & $97.36(11.92)$ & 14.43 & 2.99 \\
\hline $15-16$ months & 177 & $93.34(12.46)$ & 24.29 & 1.69 \\
\hline $17-18$ months & 147 & $89.47(12.69)$ & 35.37 & 8.16 \\
\hline $19-20$ months & 149 & $85.44(14.15)$ & 56.38 & 16.78 \\
\hline $\begin{array}{l}21-23 \text { months } \\
\mathrm{HAZ}\end{array}$ & 194 & $87.02(14.67)$ & 48.97 & 11.34 \\
\hline $13-14$ months & 201 & $-1.02(1.94)$ & 59.07 & 25.91 \\
\hline $15-16$ months & 185 & $-1.19(1.74)$ & 64.37 & 32.91 \\
\hline $17-18$ months & 147 & $-1.38(1.40)$ & 65.52 & 33.10 \\
\hline $19-20$ months & 151 & $-1.65(1.65)$ & 71.81 & 39.60 \\
\hline $21-23$ months & 212 & $-1.64(2.00)$ & 74.02 & 42.65 \\
\hline \multicolumn{5}{|l|}{ WHZ } \\
\hline $13-14$ months & 196 & $0.07(1.66)$ & 22.78 & 7.78 \\
\hline $15-16$ months & 179 & $0.22(1.37)$ & 18.67 & 7.23 \\
\hline $17-18$ months & 142 & $0.15(1.40)$ & 13.53 & 5.26 \\
\hline $19-20$ months & 166 & 0.26 (1.42) & 13.53 & 3.76 \\
\hline $21-23$ months & 206 & $0.23(1.42)$ & 15.51 & 4.28 \\
\hline
\end{tabular}

whereas the value in 21-23-month-olds was -1.64 $( \pm 2.00)$. A total of $25.91 \%$ of the young infants were stunted, whereas $42.65 \%$ of the toddlers were stunted (Table 2).

WHZ had a mean of $0.18( \pm 1.45)$, with $5.35 \%$ of the children being wasted (WHZ $\leq-2$ ). The prevalence of wasting decreased from $7.78 \%$ in infants to $4.28 \%$ in toddlers. The children in our sample were more stunted and less wasted than country-wide values of stunting and wasting, which are $10 \%$ and $14 \%$, respectively ${ }^{61}$.

Regression analyses showed a significant tendency towards decreasing means in HAZ and age-adjusted

Table 3 Regressions for developmental and anthropometric outcome measures using age as independent variable adjusted for family and household characteristics

\begin{tabular}{ccc}
\hline & \multicolumn{1}{c}{ Unadjusted $\dagger$} & \multicolumn{1}{c}{ Adjusted } \\
\hline MDI score $\neq$ & & \\
$n$ & 869 & 810 \\
$\beta(\mathrm{Cl})$ & $-1.43(-1.97,-0.88)^{\star * *}$ & $-1.23(-1.73,-0.73)^{* * *}$ \\
$\mathrm{HAZ}$ & & \\
$n$ & 893 & 832 \\
$\beta(\mathrm{Cl})$ & $-0.07(-0.14,-0.01)^{\star}$ & $-0.07(-0.13,-0.01)^{*}$ \\
$\mathrm{WHZ}$ & & 807 \\
$n$ & 866 & $0.04(0.01,0.08)^{*}$ \\
$\beta(\mathrm{Cl})$ & $0.03(-0.01,0.07)$ &
\end{tabular}

MDI - Mental Development Index (MDI) of the Bayley Scales of Infant Development; HAZ - height-for-age Z-score; WHZ - weight-for-height $Z$-score; $\mathrm{Cl}$ - confidence interval.

*, $P<0.05 ;$ ***, $P<0.0001$.

† Unadjusted models include sex; adjusted models include sex, per capita consumption, number of people in household, indigenous language spoken in household, education of head of household and family participation in community activities. None of these additional variables contributed significantly to the Bayley score or the HAZ models. However, higher WHZ was significantly associated with higher household consumption $(\beta=0.29$, $P=0.026)$.

$\ddagger$ Standardised mean for the Bayley MDI score is 100 ( \pm 15$)$. 
Bayley MDI scores during the second year of life (Table 3). Although low-SES Mexican children close to 1 year old displayed MDI scores near mean US levels of 100, average scores in Mexican children were significantly lower in older toddlers $(\beta=-1.43, P<0.0001)$. This drop-off remained highly significant after controlling for SES and parental characteristics $(\beta=-1.23, \quad P<0.0001)$. The same pattern of decline was evident in HAZ across the age spectrum, with a significant age effect $(\beta=-0.07$, $P=0.027$ ) that did not change with the inclusion of covariates. None of the socio-economic or parental covariates were significant in the regression models that predicted HAZ or MDI score. There was no significant contribution of the age variable to the unadjusted regression model predicting WHZ from age. However, with the inclusion of socio-economic and parental covariates, age became significant $(\beta=0.04, P=0.019)$, suggesting that toddlers are fatter relative to infants from the same areas. Household consumption was also a significant predictor of child WHZ $(\beta=0.29, P=0.026)$, and no other variable contributed significantly to the model.

HAZ was shown to be positively correlated with Bayley score ( $r=0.1, P=0.003)$, although it was not significantly predictive of the Bayley score when family or environmental variables were included in the analysis. WHZ was also correlated with Bayley score $(r=0.09, P=0.01)$, but not when covariates were included.

\section{Discussion}

The results show a significant decline in age-adjusted MDI scores and in HAZ when comparing children of different ages across the second year of life. We did not find that HAZ significantly predicted MDI scores when socioeconomic variables were included. The finding that low-SES Mexican children aged 13-14 months showed age-adjusted development scores close to mean US levels is very encouraging. However, average MDI levels dropped off significantly in older infants, even after controlling for SES and parental characteristics. This trend of increased vulnerability in the second year of life is similar to a trend seen in low-income infants and toddlers in the $\mathrm{USA}^{44,62}$

We were surprised to find that none of the parental or socio-economic factors that we included in the analyses contributed significantly to MDI or HAZ. However, we assessed only children from a very narrow range of SES, suggesting that there was very little variation within our sample. It is also possible that some unmeasured variables are contributing to or causing the poor outcomes that we are reporting. A longitudinal study assessing low-income children in Brazil found that family income, garbage collection, father's cohabitation, birth weight and sex were significant predictors of MDI scores ${ }^{63}$. One primary difference between that study and the one reported herein is the timing of data collection about household characteristics. For instance, income level was assessed at birth and used to predict MDI scores at 12 months of age. In our study, income data were collected simultaneously with the assessment of child development. Thus, it is possible that family income at birth is a more powerful predictor of child growth and development than current family income. Family income was a significant predictor of WHZ, which is consistent with the emerging literature about increasing wealth and increasing likelihood of overweight or obesity in Mexico ${ }^{64}$. Another variable that may be important in this population is iron-deficiency anaemia, which is known to contribute to delayed growth and cognitive development ${ }^{65}$. Unfortunately, we did not collect any measures of nutritional deficiency in this population.

Understanding the factors that contribute to poor performance on infant development assessments is difficult because scores may reflect direct neurobiological insults influencing development, under-stimulation by parents or other caregivers, or lack of exposure to experiences that promote skills. Scores may also reflect a deficit in one domain (e.g. receptive language) that interferes with the child's ability to display the skills that $\mathrm{s} /$ he possesses in the task situation. Children growing up in rural Mexico are subject to a wide variety of potentially negative influences, all of which could have an impact on both growth and mental development ${ }^{66}$. Below, we discuss three of several possible explanations for the drop in scores over time, including inappropriate infant feeding, cumulative risk exposure and delayed language acquisition.

Inadequate infant feeding including cessation of breastfeeding and early introduction of inappropriate complementary foods may, in part, explain the lower MDI scores and HAZ at higher ages. Although we do not have data about breast-feeding in this population, other surveys have shown that only $38 \%$ of Mexican infants are exclusively breast-fed at approximately 4 months of age and only $21 \%$ of Mexican children are still receiving any breast milk at 20-23 months of age ${ }^{61}$. In a sample of lowincome infants from Mexico City, the prevalence of any breast-feeding was only $25 \%$ at 6 months; in that study, breast-feeding was shown to prevent the growth faltering common in children from developing countries in the first year of life ${ }^{67}$. Infants who were breast-fed performed significantly better than infants who were not on the Bayley MDI at 18 months ${ }^{68-70}$ and 24 months, even when controlling for social and economic variables ${ }^{68,71,72}$. Thus it is possible that the low prevalence of breast-feeding in Mexico, particularly in low-income populations, could contribute to the reduction in Bayley score and height-forage across the second year of life.

A second possible explanation for the decline in average MDI scores observed in older versus younger children involves increasing exposure to risks over time. 
A number of researchers investigating developmental outcomes among children have advanced the notion of cumulative risk. The underlying assumption is that developmental outcomes are influenced by the number of social and family risk factors impacting a child's development rather than the specific type or weighting of each factor ${ }^{73-75}$. Prior work has found that higher cumulative levels of risk are related to poorer cognitive development ${ }^{1,74,76}$, psychological distress and behaviour problems $^{1,77}$, and communicative development and symbolic behaviour ${ }^{78}$. For families in persistent poverty, some risks are clearly present throughout the child's life, although other risk factors may emerge over time. Examples of these risks might include poor infant nutrition, stressful life events, poor mother-child interactions, absence of father or other available social support, exposure to environmental risks, or changes in employment status. The addition of these kinds of risk to existing factors (e.g. low parent intelligence and/or education, high family density, low-birth-weight children, parental mental health or under-stimulating home environment) may contribute to higher cumulative risk levels in toddlers than in young infants. Thus, the study findings may be the result of cumulative effects of risks associated with living in poverty across time, rather than any single explanatory mechanism.

Another possible explanation of the trend in MDI scores is the delayed acquisition of language in this low-income group. The BSID-II contains developmentally appropriate items assessing receptive and/or expressive language capabilities in children of all ages. However, the proportion of tasks on the test indicative of language skills changes with child age, reflecting the developmental advances in communicative abilities of infants and toddlers. So, at 13 months $21 \%$ of items are languagefocused, whereas these percentages increase to $40 \%$ in 14-16-month-olds, $58 \%$ in 17-19-month-olds, $62 \%$ in $20-$ 22 -month-olds and $52 \%$ in 23-25-month-olds. This pattern of required language capabilities in the assessment mirrors the pattern of decline observed in mean MDI scores in the current study sample. Low-income children in the USA build their vocabularies more slowly than higher-income children ${ }^{7}$. This pattern occurs in part because they receive less infant-directed speech and also because the speech that they hear has reduced lexical richness and sentence complexity, both of which contribute to vocabulary growth $^{8,79}$. Thus, the drop in mean scores throughout the second year of life among low-SES Mexican toddlers may reflect a common prevalence of language delays in this population relative to their same-age peers living in the USA, and may be similar to what happens with lowincome children in the USA.

Future work is needed to explore whether these differences reflect the onset of ongoing delays among Mexican toddlers or whether developmental trajectories in language or other key domains simply differ among low-income Mexican children. For instance, common cultural practices might contribute to a later onset of the language growth spurt, with achievement levels comparable to those of US children at later ages. Ongoing longitudinal research with the children in this sample will help answer these lingering questions.

Our growth results support previous findings that infants living in economically poor regions of Latin America are short for their age from early in life and that the growth deficit broadens over the first $2-3$ years of life ${ }^{80}$. However, our data suggest that on tests of development, Mexican infants begin the second year of life with similar test results to those of same-aged children in the USA. Our cross-sectional results suggest that important declines occur in both cognitive function and height-for-age across the second year of life.

We are limited in the interpretation of our findings given that we do not have longitudinal data in this population, and we are also limited in the generalisability of our results due to the restriction of our sample to semi-urban areas. Another limitation to our study is that we do not have data about critical variables, such as family income at child's birth, breast-feeding, iron-deficiency anaemia or birth weight, which may be important predictive variables for the outcomes we were assessing. In addition, we do not have any measures of psychosocial stimulation of the children by the parents, which has been shown to have a long-lasting impact on cognitive development ${ }^{81,82}$, and we do not have data from the PDI of the Bayley, which could provide additional insight into the developmental pathways for these children.

In spite of these limitations, the consistency of the growth and development findings further highlights the poor developmental status of low-income children living in semi-urban areas in Mexico, and suggests that interventions to reduce the vulnerability of children may be important during the second year of life. This developmental information provides a useful starting point for professionals making decisions about the content, timing and intensity of supportive services developed to assist Mexican families in poverty. Future work should explore the mechanisms contributing to these apparent developmental deficits, strategies for community-level interventions, and whether these observed differences persist into the third year or constitute short-term delays for the majority of Mexican toddlers in these communities. These actions are critical first steps to identifying challenges and supporting optimal development among low-income families in Mexico.

\section{Acknowledgements}

This research was supported in part by the National Institutes of Child Health and Human Development, by the Fogarty International Center (of the National Institutes of Health), and by the Mexican Government. The authors 
gratefully acknowledge the nurses and interviewers who collected the data and the families who participated in the study, and the anonymous reviewers for their comments on an earlier draft of the paper.

\section{References}

1 Brooks-Gunn J, Klebanov P, Liaw FR, Duncan GJ. Toward an understanding of the effects of poverty upon children. In Fitzgerald HE, Lester BM, eds. Children of Poverty: Research, Health, and Policy Issues. New York: Garland Publishing, Inc., 1995; 3-41.

2 Bradley RH, Corwyn RF. Socioeconomic status and child development. Annual Review of Psychology 2002; 53: 371-99.

3 Bolig EE, Borkowski J, Brandenberger J. Poverty and health across the life span. In: Whitman TL, Merluzzi TV, eds. Life Span Perspectives on Health and Illness. Mahwah, NJ: Lawrence Erlbaum Associates, Inc., 1999; 67-84.

4 Guthrie JF, Morton JF. Diet-related knowledge, attitudes, and practices of low-income households with children. Journal of Early Education and Family Review 1999; 6(3): 26-33.

5 Bradley RH, Corwyn RF, McAdoo HP, Garcia Coll C. The home environments of children in the United States. Part I: Variations by age, ethnicity, and poverty status. Child Development 2001; 72(6): 1844-67.

6 Brooks-Gunn J, Leventhal T, Duncan GJ. Why poverty matters for young children: implications for policy. In Osofsky JD, Fitzgerald HE, eds. Parenting and Child Care. New York: John Wiley \& Sons, Inc., 2000; 89-131.

7 Hart B, Risley TR. Meaningful Differences in the Everyday Experience of Young American Children. Baltimore, MD: Paul Brookes, 1995.

8 Hoff E. The specificity of environmental influence: socioeconomic status affects early vocabulary via maternal speech. Child Development 2003; 74(5): 1368-78.

9 Evans GW, English K. The environment of poverty: multiple stressor exposure, psychophysiological stress, and socioemotional adjustment. Child Development 2002; 73(4): 1238-48.

10 Koch R, Lewis MT, Quinones W. Homeless: mothering at rock bottom. In: Coll CG, Surrey JL, eds. Mothering Against the Odds: Diverse Voices of Contemporary Mothers. New York: The Guilford Press, 1998; 61-84.

11 Hsieh C-C, Pugh MD. Poverty, income inequality, and violent crime: a meta-analysis of recent aggregate data studies. In: Kawachi I, Kennedy BP, Wilkinson RG, eds. Income Inequality and Health. New York: The New Press, 1999; 278-96.

12 Karns JT. Health, nutrition and safety. In: Bremner G, Fogel A, eds. Handbook of Infant Development. Malden, MA: Blackwell, 2001; 693-725.

13 Cohen DA, Mason K, Bedimo A, Scribner R, Basolo V, Farley TA. Neighborhood physical conditions and health. American Journal of Public Health 2003; 93(3): 467-71.

14 Jacobs DE, Clickner RP, Zhou JY, Viet SM, Marker DA, Rogers JW, et al. The prevalence of lead-based paint hazards in US housing. Environmental Health Perspectives 2002; 110(10): A599-606.

15 Wamboldt FS, Ho J, Milgrom H, Wamboldt MZ, Sanders B, Szefler SJ, et al. Prevalence and correlates of household exposures to tobacco smoke and pets in children with asthma. Journal of Pediatrics 2002; 141(1): 109-15.

16 Guo G, Harris KM. The mechanisms mediating the effects of poverty on children's intellectual development. Demography 2000; 37: 431-47.

17 Grantham McGregor S, Fernald LC, Ani CC. The role of nutrition in intellectual and behavioral development in children. In: Sternberg R, ed. Environmental Effects on Cognitive Abilities. Cambridge, MA: Laurence Erlbaum Associates, 2000; 119-55.

18 Florenco CA. Nutrition, Health and Other Determinants of Academic Achievement and School Related Behavior of Grade One to Grade Six Pupils. Quezon City: University of the Philippines, 1988.

19 Chun FY. Nutrition and education - a study. Journal of the Singapore Pediatric Society 1971; 13(2): 91-6.

20 Cravioto J, DeLicardie E, Birch H. Nutrition, growth, and neuro-integrative development: an experimental and ecologic study. Pediatrics 1966; 38: 319-72.

21 Monckeberg F. Malnutrition and mental capacity. In: Nutrition, The Nervous System and Behaviour. Scientific Publication No. 251. Washington, DC: Pan American Health Organization, 1972; 48-54.

22 Powell C, Grantham-McGregor S. The associations between nutritional status, school achievement and school attendance in 12-year old children at a Jamaican school. West Indian Medical Journal 1980; 29: 247-53.

23 Freeman HE, Klein RE, Townsend JW, Lechtig A. Nutrition and cognitive development among rural Guatemalan children. American Journal of Public Health 1980; 70(12): 1277-85.

24 Jamison D. Child malnutrition and school performance in China. Journal of Development Economics 1986; 20 . 299-309.

25 Bogin B, MacVean RB. The relationship of socioeconomic status and sex to body size, skeletal maturation, and cognitive status of Guatemala City schoolchildren. Child Development 1983; 54(1): 115-28.

26 Moock PR, Leslie J. Childhood malnutrition and schooling in the Teri region of Nepal. Journal of Development Economics 1986; 20: 33-52.

27 Agarwal DK, Upadhyay SK, Tripathi AM, Agarwal KN. Nutritional Status, Physical Work Capacity and Mental Function in School Children. Report No. 6. New Delhi: Nutrition Foundation of India, 1987

28 Sigman M, Neumann C, Jansen AA, Bwibo N. Cognitive abilities of Kenyan children in relation to nutrition, family characteristics, and education. Child Development 1989; 60(6): 1463-74

29 Paine P, Dorea JG, Pasquali L, Monteiro AM. Growth and cognition in Brazilian schoolchildren: a spontaneously occurring intervention study. International Journal of Behavioral Development 1992; 15(2): 169-83.

30 Clarke N, Grantham-McGregor SM, Powell C. Nutrition and health predictors of school failure in Jamaican children. Ecology of Food and Nutrition 1991; 26: 1-11.

31 Lasky RE, Klein RE, Yarbrough C, Engle PL, Lechtig A, Martorell R. The relationship between physical growth and infant behavioral development in rural Guatemala. Child Development 1981; 52(1): 219-26.

32 Powell CA, Grantham McGregor S. The ecology of nutritional status and development in young children in Kingston, Jamaica. American Journal of Clinical Nutrition 1985; 41(6): 1322-31.

33 Grantham McGregor SM, Walker SP, Chang SM, Powell CA. Effects of early childhood supplementation with and without stimulation on later development in stunted Jamaican children. American Journal of Clinical Nutrition 1997. 66(2): 247-53.

34 Fernald LC, Grantham-McGregor SM. Stress response in children who have been growth retarded since early childhood. American Journal of Clinical Nutrition 1998; 68(3): 691-8.

35 Leslie J, Jamison D. Health and nutrition considerations in education planning 1. Educational consequences of health problems among school-age children. Food and Nutrition Bulletin 1990; 12: 191-203. 
36 Glewwe P, Jacoby $\mathrm{H}$. An economic analysis of delayed primary school enrollment in a low income country: the role of early childhood nutrition. Review of Economics and Statistics 1995; 77(1): 156-9.

37 Boissiere M, Knight JB, Sabot R. Earnings, schooling, ability and cognitive skills. American Economics Review 1985; 75: 1016-30.

38 Deolalikar AB. Nutrition and labor productivity in agriculture: estimates for rural South India. Review of Economics and Statistics 1988; 70(3): 406-13.

39 Haddad L, Bouis $\mathrm{H}$. The impact of nutritional status on agricultural productivity: wage evidence from the Philippines. Oxford Bulletin of Economics and Statistics 1991; 53(1): 45-68.

40 Strauss J. Does better nutrition raise farm productivity? Journal of Political Economy 1986; 94: 297-320.

41 Thomas D, Strauss J. Health and wages: evidence on men and women in urban Brazil. Journal of Econometrics 1997; 77(1): 159-85.

42 Sen A. Development as Freedom. New York: Knopf, 1999

43 Nelson CA. The neurobiological basis of early intervention. In: Shonkoff JP, Meisels SJ, eds. Handbook of Early Childhood Intervention, 2nd ed. Cambridge: Cambridge University Press, 2000; 204-27.

44 Black MM, Hess CR, Berenson-Howard J. Toddlers from lowincome families have below normal mental, motor, and behavior scores on the revised Bayley scales. Journal of Applied Developmental Psychology 2000; 21(6): 655-66.

45 Werner EE. Protective factors and individual resilience. In: Shonkoff JP, Meisels SJ, eds. Handbook of Early Childhood Intervention, 2nd ed. Cambridge: Cambridge University Press, 2000; 115-32.

46 Gottlieb G. Experiential canalization of behavioral development: theory. Developmental Psychology 1991; 27(1): 4-13.

47 Gertler PJ. Do conditional cash transfers improve child health? Evidence from PROGRESA's controlled randomized experiment. American Economics Review 2004; 94(2): 331-6.

48 Rivera JA, Sotres-Alvarez D, Habicht JP, Shamah T, Villalpando S. Impact of the Mexican program for education, health, and nutrition (Progresa) on rates of growth and anemia in infants and young children: a randomized effectiveness study. Journal of the American Medical Association 2004; 291(21): 2563-70.

49 Del Pozo-González B, Aparicio-Jiménez R. Criterios para la selección de la muestra de evaluación del Programa de Educación, Salud y Alimentación en localidades urbanas y semi-urbanas [Criteria for the Selection of the Evaluation Sample of the Program of Education, Health and Nutrition (PROGRESA) in Urban and Semi-urban Areas]. Cuernavaca, Mexico: Instituto Nacional de Salud Publica, 2002.

50 Lohman TG, Roche AF, Martorell R. Anthropometric Standardization Reference Manual. Champaign, IL: Human Kinetics Books, 1989.

51 National Center for Health Statistics/Centers for Disease Control and Prevention/World Health Organization. ANTHRO: Software for Calculating Pediatric Anthropometry version 1.02. Atlanta, GA: Centers for Disease Control and Prevention, 1999.

52 Bayley N. Bayley Scales of Infant Development, 2nd ed. San Antonio, TX: The Psychological Corporation, 1993.

53 Bradley-Johnson S. Cognitive assessment for the youngest children: a critical review of tests. Journal of Psychoeducational Assessment 2001; 19: 19-44.

54 Feinstein L. Inequality in the early cognitive development of British children in the 1970 cohort. Economica 2003; 70: 73-97.

55 Wright RO, Hu H, Silverman EK, Tsaih SW, Schwartz J, Bellinger D, et al. Apolipoprotein E genotype predicts 24- month Bayley scales infant development score. Pediatric Research 2003; 54(6): 819-25.

56 Gomaa A, Hu H, Bellinger D, Schwartz J, Tsaih SW, Gonzalez-Cossio $\mathrm{T}$, et al. Maternal bone lead as an independent risk factor for fetal neurotoxicity: a prospective study. Pediatrics 2002; 1(1 Pt 1): 110-8.

57 Backstrand JR, Allen LH, Martinez E, Pelto GH. Maternal consumption of pulque, a traditional central Mexican alcoholic beverage: relationships to infant growth and development. Public Health Nutrition 2001; 4(4): 883-91.

58 Solomons HC. Standardization of the Denver developmental screening test on infants from Yucatan. Mexico. International Journal of Rehabilitation Research 1982; 5(2): 179-89.

59 Shonkoff JP, Miesels SJ, eds. Handbook of Early Childhood Intervention, 2nd ed. Cambridge: Cambridge University Press, 2000

60 Kuhn D, Siegler RS. Handbook of Child Psychology, 5th ed. Vol. 2: Cognition, Perception and Language. New York: John Wiley and Sons, Inc., 1998.

61 United Nations Children's Fund. The State of the World's Children 2004. New York: Oxford University Press, 2005.

62 Hess CR, Papas MA, Black MM. Use of the Bayley infant neurodevelopmental screener with an environmental risk group. Journal of Pediatric Psychology 2004; 29(5): 321-30.

63 Lima MC, Eickmann SH, Lima ACV, Guerra MQ, Lira PIC, Huttly SRA, et al. Determinants of mental and motor development at 12 months in a low income population: a cohort study in northeast Brazil. Acta Paediatrica 2004; 93(7): 969-75.

64 del Río-Navarro BE, Velázquez-Monroy O, Sánchez-Castillo CP, Lara-Esqueda A, Berber A, Fanghänel G, et al. The high prevalence of overweight and obesity in Mexican children. Obesity Research 2004; 12(2): 215-23.

65 Grantham-McGregor S, Ani C. A review of studies on the effect of iron deficiency on cognitive development in children. Journal of Nutrition 2001; 131(Suppl. 2): 649S-66S.

66 Wagstaff A, Bustreo G, Bryce J, Claeson M, and the WHOWorld Bank Child Health and Poverty Working Group, Child health: reaching the poor. American Journal of Public Health 2004; 94(5): 726-36.

67 Villalpando S, Lopez-Alarcon M. Growth faltering is prevented by breast-feeding in underprivileged infants from Mexico City. Journal of Nutrition 2000; 130(3): 546-52.

68 Temboury MC, Otero A, Polanco I, Arribas E. Influence of breast-feeding on the infant's intellectual development. Journal of Pediatric Gastroenterology and Nutrition 1994; 18(1): $32-6$.

69 Florey CD, Leech AM, Blackhall A. Infant feeding and mental and motor development at 18 months of age in first born singletons. International Journal of Epidemiology 1995; 24(Suppl. 1): S21-6.

70 Morley R, Cole TJ, Powell R, Lucas A. Mother's choice to provide breast milk and developmental outcome. Archives of Disease in Childhood 1988; 63(11): 1382-5.

71 Morrow Tlucak M, Haude RH, Ernhart CB. Breastfeeding and cognitive development in the first 2 years of life. Social Science \& Medicine 1988; 26(6): 635-9.

72 Rogan WJ, Gladen BC. Breast-feeding and cognitive development. Early Human Development 1993; 31(3): 181-93.

73 Rutter M. Protective factors in children's responses to stress and disadvantage. In: Kent MW, Rolf JE, eds. Primary Prevention of Psychopathology. Hanover, NH: University Press of New England, 1979; 49-74.

74 Sameroff AJ, Seifer R, Baldwin A, Baldwin C. Stability of intelligence from preschool to adolescence: the influence of 
social and family risk factors. Child Development 1993 64(1): 80-97.

75 Breitmayer BJ, Ramey CT. Biological nonoptimality and quality of postnatal environment as codeterminants of intellectual development. Child Development 1986; 57(5): $1151-65$.

76 Sameroff AJ, Seifer R, Barocas R, Zax M, Greenspan S. Intelligence quotient scores of 4-year-old children: socialenvironmental risk factors. Pediatrics 1987; 79(3): 343-50.

77 Evans GW. A multimethodological analysis of cumulative risk and allostatic load among rural children. Developmental Psychology 2003; 39(5): 924-33.

78 Hooper SR, Burchinal M, Roberts JE, Zeisel S, Neebe EC. Social and family risk factors for infant development at one year: an application of the cumulative risk model Journal of Applied Developmental Psychology 1998; 19(1): $85-96$
79 Hart B, Risley TR. American parenting of language-learning children: persisting differences in family-child interactions observed in natural home environments. Developmental Psychology 1992; 28: 1096-105.

80 Martorell R. Results and implications of the INCAP follow-up study. Journal of Nutrition 1995; 125(Suppl. 4): 1127S-38S.

81 Walker SP, Grantham-McGregor SM, Powell CA, Chang SM. Effects of growth restriction in early childhood on growth, IQ, and cognition at age 11 to 12 years and the benefits of nutritional supplementation and psychosocial stimulation. Journal of Pediatrics 2000; 137(1): 36-41.

82 Walker SP, Chang SM, Powell CA, Grantham-McGregor SM. Psychosocial intervention improves the development of term low-birth-weight infants. Journal of Nutrition 2004; 134(6): 1417-23. 